This item was submitted to Loughborough's Research Repository by the author.

Items in Figshare are protected by copyright, with all rights reserved, unless otherwise indicated.

\title{
The chain of information provision in the villages of Malawi: a rapid rural
} appraisal

PLEASE CITE THE PUBLISHED VERSION

PUBLISHER

(c) Elsevier

LICENCE

CC BY-NC-ND 4.0

\section{REPOSITORY RECORD}

Sturges, R. Paul, and George Chimseu. 2019. "The Chain of Information Provision in the Villages of Malawi: A Rapid Rural Appraisal”. figshare. https://hdl.handle.net/2134/557. 


\title{
THE CHAIN OF INFORMATION PROVISION
}

\author{
IN THE VILLAGES OF MALAWI:
}

A RAPID RURAL APPRAISAL

PAUL STURGES and GEORGE CHIMSEU

Published in International Information and Library Review (1996) 28, 135-156.

\section{INTRODUCTION}

This is an account of a small, swift and inexpensive research project in rural Malawi. ${ }^{1}$ Its aims were twofold: first to give useful guidance to Malawi National Library Service in meeting the information needs of village communities, and second to throw some light on the confusing messages which emerge from the published studies of information and communication in the villages. The specific objectives of the project were to examine the chain of communication between providers of information (chiefly government ministries and agencies) and the ordinary citizens in the rural communities who are the intended users of this information. This was done at three points: in the agencies which create information packages for dissemination; amongst the intermediaries who actually do the dissemination; and with the inhabitants of the villages, whose needs the packages are intended to serve. Opinion and experience was collected which reflected the communication process from the viewpoint of each participant group. By this means, strengths and deficiencies in information transfer were identified. The results are a contribution towards understanding an information environment which presents unusual degrees of challenge for both the information seeker and the information worker.

Indeed, the African village, impoverished, neglected, and frequently isolated by geography, language and culture, represents one extreme in a global range of information environments which stretches from virtual reality back through to painfully hard reality. That it is a fascinating and complex environment was recognised by European travellers with their tales of a dark and mysterious continent, but the work of Doob, ${ }^{2}$ published in 1961, was the first substantial modern account of communication and therefore to a certain extent, by inference, information seeking in African society. Since then, the only major study has been that of Scribner and Cole in $1981^{3}$ on literacy in Africa. A certain number of other studies which do throw some light on information seeking have been carried out, but accounts of them are scattered through the published and semi-published literature of a number of disciplines ${ }^{4}$ including education, communication studies, development studies, social anthropology and economics.

Information science itself has neglected what is basically a non-literate society. Adimorah in a 1983 analysis of the failures of public libraries in Nigeria, found it necessary to suggest that "Further research is needed on the information needs of Nigerians and their information gathering habits to enable public library directors to plan society-based services and create a true library tradition. ${ }^{5}$ In fact in Nigeria itself some important research of just this type had already been done, and Olabimpe Aboyade's report of her RUDIS project was perhaps the first significant contribution from within the discipline. ${ }^{6}$ Quite a proportion of worthwhile studies concern farming communities, for instance, that of Oladele on the expressed information needs of farmers, ${ }^{7}$ Adimorah's survey of farmers' information needs in Imo State, Nigeria, ${ }^{8}$ and Aina's research from the same period. ${ }^{9}$ There has been less research with a whole community scope, but Mchombu's INFORD survey in Botswana, Malawi and Tanzania is a major 
exception to this generalization. ${ }^{10}$ The findings of a small, but interesting, group of studies which say something about Malawi and its immediate region will be discussed in relation to the results of the present study, later in this paper.

What the literature and personal observation reveal is that the African village has a self-contained, holistic system of knowledge and beliefs. ${ }^{11}$ This system has successfully offered passive resistance to the spiritual pressures of colonialism and the modern African state, and is the reason why development planners have talked of the need to 'capture the peasant'. The indigenous knowledge resouces of the village include history, religion, creations of the imagination, agricultural lore, traditional herbal medicine, and much more, all retained in the human memory and orally transmitted. The existence of the system influences information-seeking patterns, and indeed, perceptions of information need. Thus, studies show large proportions of the population cannot concretize their information needs, or deny that they ever experience the need for new information. ${ }^{12}$ The information needs which do emerge are largely related to agriculture and other economic activities, healthcare and sanitation, but there is also a consistent desire for less immediately practical material, including devotional literature. ${ }^{13}$

At the same time, governments are seeking to encourage the shift from self-sufficiency towards production for the market, to alleviate the everyday hardships of rural life and to provide some disasterprevention mechanisms for communities at risk from a range of potential catastrophes. For informationrelated aspects of this they employ rural extension services, mass media, and, to a limited extent, printbased services. Whilst it can be shown that these systems all operate in a top-down way which prevents them from achieving full effect, modern communications have, nevertheless, begun to erode the confidence of communities in their traditional knowledge systems. It is in this general, region-wide context that the investigation of information and communication in a rural milieu, to be described here, was set. It is also necessary to identify the specifically Malawian setting.

\section{THE SETTING}

Malawi is a small, land-locked state on the edges of the southern part of the east African rift valley. It has a wide range of climates, soils and vegetation, with much good agricultural land. Its more than eight million inhabitants, speaking a number of mother tongues, but using Chichewa and English as national languages, are packed into a densely populated territory. Formerly a British colony, it became independent in 1964, under Kamuzu Banda, who practised an increasingly personal and oppressive style of government, unusual for its cordial relations with South Africa. A gross domestic product of $\$ 218$ per head in 1993, makes it one of the world's poorest countries, and as many as $80 \%$ of the population are estimated to live below the poverty line. More or less universal primary education is followed by a secondary system with only about 30,000 places, and very restricted access to higher education. The system has, however, succeeded in developing to a very impressive level the talents of those Malawians privileged to gain full access. A referendum in June 1993 introduced multi-party democracy and in the elections of May 1994, Kamuzu Banda was defeated. The ending of his regime's suppression of the expression of information and ideas has created an atmosphere of open comment and debate, which presented an ideal environment for the project reported here. Newspapers, for instance have increased from the one official title to a fluctuating number of lively, but financially frail, new titles. At the same time Malawi is a country whose backwardness in terms of modern communications is illustrated by its lack of a television service and its access to little over 50,000 telephones.

The larger proportion of the population (about 80\%) is resident in the rural areas, fully engaged in agricultural production. The illiteracy rate in Malawi is one of the highest in the world (quoted at $59 \%$ by 
the 1987 Population and Housing Census). The Director of the National Library Service, Roderick Mabomba, has observed that "Rural development is the basis for economic development in Malawi and information is an important ingredient in any development process. People in the rural areas, whether literate or not, should have access to any kind of information which will help them to be more capable and productive in their daily occupations, discharge their social and political obligations efficiently and to become better informed citizens generally. The public library service should facilitate the transfer or flow of appropriate information among rural communities, using appropriate and suitable or convenient methods and media. The efforts of other information agencies in rural areas should be recognised and the desirability of co-ordination kept in mind." ${ }^{14}$ For this reason the Malawi National Library Service has an Extramural Services Department which, amongst its range of activities, serves the National Adult Literacy Programme (NALP) by providing reading material to a network of Rural Community Information Centres. ${ }^{15}$

Of the other agencies referred to by Mabomba, it is most important to mention the Ministry of Agriculture and Livestock Development at this point. It has the nation's largest network of extension activities, and its Field Assistants are active in every part of the country. Malawi is divided into eight Agricultural Development Divisions, subdivided into Extension Planning Areas (EPAs), for this purpose. Each EPA has a local office, from which the field activities are administered. The Ministry creates a flow of information to be delivered, by this network, to the farmer families in the field through its Agricultural Communication Branch (ACB). It provides information input for the extension process as circulars, newsletters, booklets, radio broadcasts, cine film projections and puppet shows.

\section{METHODOLOGY}

The methodology of this project was explicitly qualitative rather than quantitative. Other recent research on information in rural Malawi, including that of $\mathrm{Mchombu}^{16}$ and $\mathrm{Uta}^{17}$ lends itself to quantitative analysis. The existence of this earlier work opens the way for research which is less concerned with statistical validity, and more directed at exploring people's experience and opinions for the lessons they offer. The validity and appropriateness of this methodological approach for research in the rural areas of less-developed countries has been described and defended, notably by Chambers, ${ }^{18}$ and is discussed in more detail elsewhere by the present authors. ${ }^{19}$ The essence of the argument for a qualitative approach is that it is more open to the unexpected than strictly quantitative methods. In structuring the project, an approach pioneered in the development field, and referred to as either Rapid Rural Appraisal, ${ }^{20}$ or, subsequently, Participatory Rural Appraisal, ${ }^{21}$ was used as a guiding principle. The approach is 'rapid' because of the need for development-related research which produces useful conclusions and implementable recommendations within a timescale dictated by urgent human need. Amongst its distinctive features are: the use of more than one method to approach the research problem, substantial use of local knowledge, flexibility, and use of conscious judgement.

With these principles in mind, three schedules were devised, which set out the topics to be introduced in case study visits to information providers, in interviews with intermediaries, and in group discussions with information users. The topics were expressed in the form of very open questions, to be used to prompt, but not direct response from those interviewed, and participants in discussions. There was space on the schedules for notes of responses received, but these notes were to be supplemented by more detailed notes made after the interview or discussion. To test the accuracy of the method, some of the sessions were tape recorded. However, the validity of the method was not in serious doubt, since it is one developed and used to good effect by the pioneer social investigators of the nineteenth century. ${ }^{22}$

The questions in the three schedules covered much common ground but naturally had elements directed uniquely at their own target group. Providers were asked for details of the services and products they 
created. Their policy objectives and the role of sponsors at this level were explored, as were the initiation and evaluation of programmes. Discussion on achievements, problems and future programmes was prompted. The intermediaries were asked about the subjects on which they needed information to pass on to the community. They were asked to discuss and evaluate the information they currently received or to which they had access. They were also asked about problems experienced in obtaining and passing on information, and encouraged to identify desiderata. Finally, the users were asked for the topics about which they needed to know; the ways, formal or informal, in which they currently obtained information on these; the trust which they put upon the sources of information they used; and the effectiveness, for their purposes, of formal information channels. These three research instruments were used flexibly, with the order of topics varying according to the flow of discussion, and respondents being allowed to dictate the emphasis placed on topics. The schedules were treated as something to be modified according to the lessons of experience in using them. Visits to providers and interviews with intermediaries were conducted in English, and the discussion groups with users were in Chichewa. Research notes were kept entirely in English.

The visits to information providing institutions in Lilongwe were at the Ministry of Agriculture's Agricultural Communication Branch, the Health Education Unit, the Department of Information's Regional Office, the AIDS Secretariat, and the National Library Service's Extramural Services Department. Two communities, Dowa West and Mangochi/Monkey Bay, were selected for the interviews with intermediaries and group discussions with users. They represent something of the different geographical and economic circumstances, and different social and political complexions, of Malawi. Dowa West is an almost exclusively agricultural community of a traditional and conservative character. Chichewa is the main language, and the influence of the former ruling party is still strong. Mangochi/Monkey Bay is more prosperous, with fishing, tourism and craftwork. It has many Yao speakers and Muslims amongst its population.

In Dowa West interviews were conducted with 26 intermediaries (EPA1 four, EPA2 three, EPA3 three, EPA4 six, EPA5 ten) out of a total establishment of 63 . Group interviews were conducted with villagers from a single community in each EPA (Zakeyo, Galan'gombe, Diamoni, Simbi, and Nyengere). The villages were selected to provide a geographical scatter across the area and to represent different types of community. ${ }^{23}$ In Monkey Bay/Mangochi there were interviews with four intermediaries in Mbwadzulu EPA and eleven in Nankumba EPA. There were also nine group interviews with villagers: in Nankumba village (a group of men and a separate group of women), Binali (mixed group), Nankwali (mixed group), Chimphamba (mixed group), Msumbi (women), Phumula (mixed group), Nsomba (women), Monkey Bay Trading Centre (women).

In preparing a narrative from the research notes, the researchers made a distinction between three types of material which the interviews and discussions produced. The first consisted of more or less universal and conventional sentiments, for instance the need for more and better information on crop production techniques or health and hygiene. The second took the form of frequently occurring points (obtained from anything between $30 \%$ to $70 \%$ of respondents in a category) which seemed to represent considered judgement or strongly felt opinion. The last type was occasional and interesting individual points which arguably had value even though they were based on opinions not widely held. The strongest emphasis was placed on the second category, because it offered to reveal more than the conventional, and yet avoided the danger of following eccentric lines of thought. Because the numbers concerned were small, it was decided not to express them as percentages, with the often-spurious claim to precision that this seems to imply, but merely to present them as totals, the significance of which the reader is invited to join the researchers in assessing. The aim was to identify informed and widely-held views which offered the potential for change, experimentation, and further research. 


\section{RESULTS}

\section{INFORMATION PROVIDERS}

The case study visits to information providers were included in the research programme on the grounds that an understanding of the formal sources of information was needed before the dissemination and reception of information could be understood. ${ }^{24}$ Discussion during the visits centred on their policies, methods of working, and their products and services. In particular, any indication of the existence of mechanisms for responding to expressed need was sought.

The Ministry of Agriculture's Agricultural Communication Branch is the chief agency communicating with the rural population, and is geared to transmit research results to farmers in acceptable information packages. This chiefly means short leaflets intended to brief extension agents, but also includes publications like the magazine Za Achikumbi (an unpretentious illustrated collection of agriculturerelated articles), and the handbook Guide to agricultural production in Malawi. The Branch provides the necessary writing and editing skills and print facilities to serve this purpose. The USAID-sponsored Communication Project, 1987-1991, was explicitly designed to enable the Branch to work from field data about information needs. However, it was acknowledged that, despite this, messages were not always wholly relevant. Defects in the supply of agricultural inputs were identified as common sources of dislocation between the message and the activities it concerned.

The Ministry of Health's policies concentrate, at present, on prevention and management of communicable diseases. The information dissemination requirements of this are met by the Health Education Unit, which responds to demands for information materials from specific projects. So far it has served twenty two different programmes in this way. For instance, the excellent posters designed and produced by its staff are widely available. They illustrate the need for safe sexual practices in the avoidance of AIDS, or the need to follow the instructions of medical staff, rather than unqualified 'medical' personnel, over the treatment of diseases. The use of performances of songs and playlets containing health messages by the Ministry's Katemera Band, a nine-strong touring ensemble, is a further means employed by the Unit. However, the Unit does not have the capacity for an overall needs assessment relating to health information. The various agencies and projects set their own agendas to which the Unit responds. Thus, the AIDS Secretariat is one of the projects which uses the services of the Unit. The first phase of its programme has been the raising of AIDS-awareness, but it is now entering the more difficult phase of attempting to persuade people to change behaviour patterns. The importance of close liaison between the agency which has the project and the Unit which provides communication materials on its behalf is clearly crucial.

A rather similar relationship is that between the Malawi National Library Service's Extramural Services Department and the national Adult Literacy Campaign. The Extramural Services Department provides reading matter to community information centres, which it also administers. At present it only has informal means for obtaining feedback, and is very much dependent upon the accuracy of the assessments of need made by the Campaign's administrators.

The way in which such bodies essentially act as channels for passing on messages chosen by those in authority is further illustrated by the work of the Department of Information. Its branches are effectively parts of a news gathering and dissemination agency, but its chief purpose is to interpret government policy to the population. For instance it is currently, in conjunction with the European Union and the United Nations Fund for Population Activities (UNFPA), disseminating family planning messages on the radio. This arises directly from the Malawi government's strong commitment to sensitizing the people to the dangers of overpopulation, such as food shortages, deforestation, and shortage of land for cultivation. There appears to be no evidence that the messages are especially tailored to achieve optimum 
receptivity, and indeed there was a strong sense that the Department may be broadcasting mainly to itself.

There is every indication that these sample institutions, chosen for case study visits are reasonably typical of the whole range of information providers. They have enthusiastic and capable staff with the ability to provide important information products and services, despite serious funding limitations. However, notwithstanding the evidence that the organisations did have some access to guidance on the needs of information users, the visits suggested that each of these organizations is essentially geared to one-way communication - top down. Mechanisms which would enable the intermediaries and information users in the rural communities to set the communication agenda, and claim ownership of the communication process, are clearly not in place.

\section{INTERMEDIARIES}

The people identified as the most significant intermediaries, for the purposes of this study, were all formally employed for information dissemination, and whilst the importance of communication by groups like schoolteachers, ministers of religion, politicians, and traditional leaders was recognized, they were not included in the interview programme. Those interviewed were mainly Ministry of Agriculture Field Assistants, along with some Farm Home Assistants and Community Development Assistants. They are referred to in what follows as extensionists or extension agents. Their usual qualification is a twoyear post-school diploma and the length of experience of those interviewed varied from a few months to decades. They live close to the community they serve, in simple houses provided by their employers. We found them committed to their work, willing to talk about it, and often capable of considerable insight. Some caution is required in using responses from extension workers because of the uneven distribution of contact with farmers that is typical of such services worldwide. As Mhone pointed out in 1992, "Although the government has insisted that all smallholders are to benefit from the various supportive services, the data clearly shows a bias in favour of the top [social] group." ${ }^{25}$ Yet, despite this, the scale of the extension agents' activity throughout the rural areas is such that their views have to be taken seriously.

We travelled the highways and byways of the extensive district of Dowa West to interview 26 out of a total establishment of 66, usually in their homes or wherever they happened to be working. In Mangochi/Monkey Bay a further 15 were interviewed. Thus the numbers of respondents expressing particular opinions cited in what follows are from a basic population of 41. Except in some matters of detail, what emerged from the interviews with the extensionists in the two areas was consistent, and is therefore presented here as a single narrative.

The first topic introduced in our interviews (the subject matter they dealt with) revealed that, whatever the formal designation of their post, the extensionists all had to respond to demands for information relating to agricultural production. Within this dominant category, more than three quarters of them (33 out of 41) stressed the daunting breadth of response that their clients could require. Pest and disease control for animals and crops, cultivating less familiar crops such as tobacco or some types of fruit, construction of kholas for rabbits, and many, many other agricultural topics occurred. Topics related to agriculture, such as forestry; wells, boreholes and other aspects of water supply; appropriate technology including skills like tinsmithing, were also frequently mentioned. Health and family planning matters, literacy and adult education, also occurred with great frequency. Nearly half of them placed a particular emphasis on a strong need for new technical information (18), or details of relevant government policy (18), and a slightly smaller number (15)identified the importance of the practical basis of what they were required to pass on. Six respondents particularly emphasised the role of change and fluctuation in this, citing, for instance, the way in which drought conditions led to frequent requests for information on food preservation techniques, such as whether to keep maize as cobs or flour. Prices for agricultural products 
were similarly a constant concern because of the way they changed. The over-riding impression is that the extension workers needed information on topics that were likely to stretch the scope of even a very well-informed individual. What is more, as one of them put it, there is a great need for updating of their knowledge in a world which changes all the time.

When asked about their sources of knowledge and information, all but one or two of those interviewed cited the fortnightly training sessions held for them at each Extension Planning Area (EPA) office, when they received the messages packaged by the Agricultural Communication Branch of the Ministry. Their reliance on these sessions is almost total. None of the extensionists questioned the principle of such a system as the main information nexus of their work. Some, indeed, went further, expressing this as uncritical approval of the quality of the communication process. For these, the training defined their responsibilities and provided them with what they needed to carry them out. The messages, put over orally and backed by brief information sheets, could be taken almost intact, and passed on to the farmers at the regular meetings at the block (the smallest group of family dwellings served). More than half (28) endorsed the effectiveness of the written materials they received. A small number of the extension agents (6) also said they valued the sessions because they experience two-way communication with the Development Officers and subject specialists who conduct the training. However, there was also a detectable current of critical opinion overlaying the basic acceptance of the communication system. Sources of information from outside the immediate system were very infrequently mentioned, only six respondents crediting word of mouth as a source and five mentioning radio. Three emphasised the value of their own experience, and two mentioned their own informed observation.

The opinions voiced on the quality of information they received included criticisms which fell into three main categories. The information was criticised on grounds of poor timing, excessive flow, and excessive range of topics. More than half of the respondents (24) did endorse the timing of the messages, but this was often a grudging admission that the timing wasn't wholly adrift. The minority (17) who directly criticised the timeliness of the messages claimed that the chain of communication from the Ministry to the extension worker had too many links, which could result in delays. 'Red tape' often contributed to this, and legitimate staff absences (e.g. for funerals) at the Rural Development Project (RDP) and EPA offices, when cover was not automatically available, could all too easily compound such difficulties.

An excessive flow of messages, requiring the extensionists to select which to pass on and which to regard as for their own attention only, was alleged quite frequently (12 respondents). The training sessions were said to be rendered less effective by the number of topics covered. The time to give the messages the necessary evaluation that they required was seldom available, and extensionists were faced with the dilemma of whether to pass on messages dutifully and mechanically, or to filter some out as of less immediate relevance. This opinion was a reflection of discontent with a lack of two-way communication over message content discernible in responses on a number of topics. This viewpoint was much more common than the satisfaction with the opportunities for dialogue which a few agents did say they felt (as mentioned above).

A sense that an excessive range of topics was covered in the messages also emerged in some responses (14). This opinion was, of course, a further reflection of the one which was noted earlier (that the job itself required a dauntingly wide range of knowledge). Some messages were outside the range of the extensionists' knowledge and hard to absorb. Since only a basic outline of a topic was usually provided, extensionists sometimes felt inadequately prepared to pass on messages on unfamiliar topics and respond to farmers' questions. Some messages were of limited relevance to the communities to which they were supposedly addressed.

In disseminating the messages, the extensionists are expected to work through demonstrations to groups 
of farmers on training plots at the block. Most (28) expressed a direct endorsement of this method, but frequently they suggested that its effectiveness had withered under prevailing difficulties. They vary the extent to which they communicate through local community leaders, or supplement the work at the block with personal visits to farmers (rated as the most important method by 14). Several (13) place a high value on the support which radio announcements provide to their work, by stimulating interest and reinforcing the messages. However, this opinion was usually qualified, by the proviso that far from everyone has a receiver and that broadcasts are often not made at convenient times for listeners. Radio messages were also regarded as insufficiently coordinated with the extensionists' programme of work and, indeed, frequently ill-synchronized with the farmers' need for the information they contain. The Ministry's yellow vans (bringing film shows to the villages) were mentioned as a support one or twice, but it was said that they came too infrequently to be a consistent help, and publications like $\underline{\mathrm{Za}}$ Achikumbi, though highly valued by the farmers, come in totally inadequate quantities for distribution. At present, the inescapable conclusion is that the extension agents believe that dissemination stands or falls upon the success of oral transfer of the messages.

When asked to discuss their information work in terms of problems and possible solutions, the extensionists brought up a wide range of topics, often with only two or three putting forward any one opinion. Some were concerned with the ability or willingness of the farming community to absorb the messages. Amongst a variety of reasons suggested for this, was many farmers' financial indebtedness and consequent shunning of contact with officials. Lack of materials (fertilizers, weedkillers, etc) for practical demonstration purposes was a serious hindrance. Simple transport was a major difficulty for extension agents serving very widespread areas on foot, or on a bicycle, along unreliable dirt roads. Lack of coordination between agencies involved in rural development was cited as a difficulty. The sheer number of clients (800 or more farming families each is normal) naturally bulked large in this identification of problems.

Many of the respondents did, however conceptualize their problems in information terms (again with each opinion mentioned here tending to appear only two or three times). Slow official response to requests for specific information (such as a particular agent's needed for facts on bee-keeping), or poor response to initiatives that called for information back-up (such as a Veterinary Assistant's encouragement of rabbitry) were cited. The need for access to courses, which many mentioned, was clearly related to this sense of needing more information almost as much as it represented a desire for opportunities for personal advancement. In addition to this, there was a frequent and clearly expressed desire for access to written materials for reference in times when information was needed. The District or EPA offices seldom had more than one or two books for this purpose, and respondents cited their need for books on practical subjects like nutrition, cookery, and livestock keeping, as well as on relevant background topics like the activities of funding agencies, such UNICEF, USAID or the Save the Children Fund. They relied greatly on the Ministry of Agriculture's Guide to Agricultural Production in Malawi, but this could only meet basic information needs. Some also wanted books which could help them with correspondence courses.

\section{INFORMATION USERS}

The villagers whose gratifying willingness to discuss their experiences and perceptions with the researchers was so important to this project, were too few in number, and too much self-selected to constitute a scientifically-reliable representation of community opinion. However, the villages in which they lived were chosen from two distinct regions and they did cover a range of conditions, from comparatively prosperous trading centres to tiny hamlets weighed down by poverty. The fourteen groups varied in number from six or seven to thirty or forty people, and in each case a reasonable proportion of them actually contributed to discussion. Care was taken to observe group response to the statements of individuals and note-taking favoured points endorsed by the group. The groups mainly included both 
men and women, sometimes the one in the majority, sometimes the other, but a few women-only groups were seen in the Monkey Bay/Mangochi area. Trouble was taken to ensure that anyone willing to talk had their opportunity and, in particular, the contribution of women was successfully encouraged. Nevertheless, it is only possible to report what was said as opinions obtained in the field.

It usually took some time to explain the opening topic for discussion (what type and form of information people needed). Its main value was that it prepared the group to answer on the topics which followed. After the initially slow response, the topics the groups cited proved to be fairly predictable. The subjects they mentioned accorded very much with the extension agents' evidence: agriculture, health, including family planning, hygiene, including water supply, education and literacy, credit and loans. Matters of concern to small businesses were mentioned several times in Monkey Bay/Mangochi, particularly by the all-female group in Monkey Bay Trading Centre. Four groups did, however, mention a desire for information related to religious matters, which had not emerged through the accounts given by the agents. Also, a firm opinion emerged from as many as six groups that it was the availability of inputs for agriculture which was the chief concern, not information. In general, the groups from the Monkey Bay/Mangochi area were more outspoken in their expression of their needs, but the essential content of what they said was similar to the opinions expressed in Dowa.

When asked about the transmission of information, most of the groups had strong opinions, and in particular about the way in which extension services were functioning. There was a very consistent sense that word-of-mouth communication by official representatives, probably through a regular channel such as the meetings at the block, was the most effective and useful means available. In some villages, the extension agents were said to be the only outside visitors and the only regular face-to-face contact with the rest of the country. However, strong and varied criticisms of the way the system is functioning were expressed by at least eight of the groups. This type of opinion was, in general, more vociferously expressed in Monkey Bay/Mangochi. Speakers quite explicitly identified the extension system as being in crisis and sometimes, particularly in conservative Dowa, associated this with the introduction of a multi-party democratic system. The extension agents are widely said to be no longer visiting the blocks on a regular basis. One or two, indeed, are said to be more concerned with their own farming activities and with manipulating credit opportunities to their own advantage. Setting aside such accusations, women feel particularly neglected, with Farm Home Assistants hardly reaching the more isolated communities. For health information, the women feel compelled to walk long distances to the clinics. The picture the discussions revealed was of a system, in which the villagers believed, functioning extremely badly.

Radio was frequently mentioned as an alternative or supplement to information received through the extension services, usually without prompting from the interviewers. The information provided by radio was considered to be useful, but not usually without the endorsement of some other trusted source, preferably one which had the capacity to respond to questions. Radio messages were often broadcast at unsuitable times of day and too few people had receivers for the medium to be truly effective. The suggestion that official help, probably in the form of communal radio reception facilities, would be useful, was made by one group. The yellow vans, with their film shows, were mentioned as an attractive option, but it was consistently pointed out that they hardly ever reached the communities, and when they did come, they were more of a source of entertainment and diversion than a true information resource. Posters at the trading centres were mentioned, more or less in passing, on several occasions as a meduim which did put over simple messages in a direct way.

Print was mentioned in virtually every community as a valued and trusted source. The problem which groups identified with it was its extreme scarcity, rather than the inability of large numbers of the people to read it. Illiteracy was not mentioned as an obstacle, because there was always someone who could read text out loud, and illustrations could make the meaning clearer. Of the communities visited, 
Nyengere (Dowa West) was the most committed to print as an information medium, and its Rural Community Information Centre (RCIC) is a source of great pride. The researchers were, for this very reason, invited to eat nsima with Chief Nyengere in the simple room which houses the Centre. Newspapers were not, at the time of the research, reaching the villages (clearly owing to the complete shake-up of publishing arising from the multi-party system). Za Achikumbi was not reaching the villages either, and this was several times cited as a cause of frustration. Infrequent visits by the extensionists were blamed for its absence, although when it did appear it was never in enough copies to satisfy demand. The post-literacy booklets, made available by the National Library Service through the RCICs, were mentioned as useful on several occasions.

In addition to their opinions on these formal sources, the groups were very clear as to their feelings on informal channels of communication. These have clearly not lost their influence in rural Malawi. Information was described as passing between people at various types of gathering, and groups variously mentioned funerals, beer brewing and drinking occasions, group mat-making and grain-pounding sessions, games of bawo, etc. More formally-constituted events, such as public health meetings, literacy campaign meetings, and church services were all cited as providing informal, as well as formal, means of information transfer.

The role of chiefs and village headmen was also important, especially in Dowa, where it was generally mentioned by the groups. The chiefs do call meetings for information purposes and at these they pass on what they themselves have been told in their capacity as representatives of the traditional authorities which are part of the Malawian system of government. On occasion (forestry campaigns were cited by one group) this could be the principal means by which certain categories of information were transferred. Respondents in several groups also stressed the need for chiefs to be involved in formal information transfer, because of the authority their involvement imparted to the process. Group after group made distinctions between the weights to be attached to various sources of information. Information obtained at informal occasions like beer-drinking sessions is often the first introduction to developments, but as rumour, it is not fully trusted. Once it can be cross-checked against some other source, such as a message passed on by an extension agent, or a radio announcement, then it is given more credence. For it to be wholeheartedly accepted, it also requires the endorsement of chiefs and other local leaders.

Finally, a dimension of difficulty which was frequently referred to was transport, both for themselves, to points where information was available, and also for extension agents, so as reach the villages. The deterioration of roads in the rainy season was an endemic problem, but lack of effective bridges over rivers and streams (a problem experienced by the researchers themselves on two or three occasions)was particularly important in specific instances. Moving people from place to place is still an essential feature of the movement of information for rural Malawians, and none of the groups expressed an opinion that this was likely to change in the near future.

\section{DISCUSSION}

The validity and usefulness of research of this kind is that it reflects the lessons of experience, with all their contradictions and complexities, and that it is therefore particularly helpful in the interpretation of other, more formal, research. We are confident that what we present is very strongly rooted in the everyday experience of all those whose activities form part of the information chain in rural Malawi. As far as other research is concerned, it was suggested earlier that although this has not been plentiful it has produced interesting, but sometimes confusing, results. Since there is quite a small number of specifically Malawian studies, for the purposes of this discussion we have also looked at results obtained in other countries. We acknowledge that this brings with it a real risk of seeking to compare results which relate to local circumstances so different that the comparison is meaningless. Whilst there is some 
case for saying that there are fundamental characteristics of African village life which apply across the whole of the sub-Saharan region, comparison with more distant African countries has not been ventured here. This reduces, though does not eliminate, the risk.

First of all, our assessment of the information and rural communities accords well with that which emerged from the Ministry of Agriculture's own Malawi Agricultural Research and Extension Project (MARE) of the early 1990s. The Communication element of this identified a problem (among others) of "Lack of two-way information flow between and among researchers, extension workers and other entities in the agricultural technology development testing or transfer process." ${ }^{26}$ We would broaden this to say that not only the extension workers, but also the farmers themselves, are not effectively part of a two-way flow of information of any kind arising from the centre. This conclusion is borne out by the findings of Mpachika and colleagues whose study of extension and farmers in Malawi suggested that, although they supported the system, "Farmers are not sufficiently involved in deciding points to be stressed by the extension workers on field visits, nor in the extension program planning process." ${ }^{27}$ The potential dangers of this one-way communication are not merely that the farmers will fail to receive information which might have benefitted them, but that the capacity of the system to give timely warning of problems is underdeveloped. That this is a real issue is illustrated by the disaster in the Nkhata Bay area in 1986, when the mealy bug destroyed the local staple crop of cassava. It took informal reports of abnormally high mortality rates to alert the authorities, because the official channels of feedback were ineffective. ${ }^{28}$

That there is nevertheless considerable trust in the extension workers, is supported by a number of studies. When asked a rather open question about their sources of information (similar to the one introduced into our group discussions with villagers), people mentioned extension workers very frequently. Namponya, for instance, found from his own interviews with over 200 farmers in Malawi that 59\% saw extension workers as their main source of information, and that other studies in Nigeria and Kenya asking a similar question produced very similar percentages. ${ }^{29}$ The MARE Project, mentioned earlier, even obtained a response that $72.5 \%$ of farmers would consult extension workers for agricultural advice, and only $13 \%$ neighbours and family, ${ }^{30}$ but the scale of this response is probably not surprising when the survey was conducted under the auspices of the Ministry. When the questioning is a little more specific and respondents do not feel any obligation to endorse the system, their answers take on a very different look. Francis and Rawlins-Branan's survey in Zambia produced a response that farmers' chief problems were overwhelmingly concerned with financial and other inputs. ${ }^{31}$ In such cases a total of $56 \%$ of farmers felt that government and official credit sources should advise and help. Only a little over $10 \%$ cited extension workers, and other local individuals were also mentioned by small percentages of respondents.

The diversity of sources which farmers would use is also evidenced by Kaniki's study of 1000 Zambian farmers. ${ }^{32}$ But his most interesting finding was not that they used many sources of information, but that $74.7 \%$ relied on personal experience 'often' and that 34.9 also cited family and neighbours as a frequent resort. There is a distinction underlying this that does not fully emerge from these studies, and this creates the appearance of contradiction. This is clearly because so many of the researchers have been prisoners of the structure of their questionnaire or interview schedule. Their questions have tended to produce answers related to different sources of information and advice which simply rank them against each other in terms of preference or trust. A method, such as our group discussions, which is more open to the more subtle distinctions of what people might think or do in varied circumstances allows the interrelation of these sources to emerge, and suggests that they are not simple alternatives at all.

For instance, it was much clearer from what the participants in our group discussions told us, that farmers are usually talking about how they obtain their basic fund of information when they mention very immediate sources. Of the published studies, Mungunda and Mumbuna make this distinction better 
than others. ${ }^{33}$ They show that a total of $84 \%$ of the farmers they interviewed attributed their basic knowledge to very local sources (elders in the community or, indeed their own experimentation). However, when seeking new knowledge 62\% looked to extension services, and a further $14 \%$ to other agricultural institutions. This also fits well with the findings of McClymont in Zimbabwe. ${ }^{34} 53 \%$ of the small commercial farmers he surveyed learned from experience, $23 \%$ from neighbours, and only $12 \%$ from extension workers. However, 95\% did also say that they had at some point or other turned to the extension services and gained something that was useful from them. Interpreted in the light of our research, the published studies show that farmers obtain the basics of their knowledge within the community; that they would, in principle, turn to extension workers with a specific problem in mind; but that in many cases they would actually look elsewhere.

All this is broadly compatible with the findings of Mchombu who perceived a tension between traditional and modern points for the exchange of information and news in Malawian villages. ${ }^{35}$ "Place of worship and market place rival health centre as the most common location for information exchange". He also found that in his two case study villages $78 \%$ and $67 \%$ of villagers cited the village chief as their first resource for development-related information. In the first village $53 \%$ also cited the local extension worker as their second preference (although only $14 \%$ nominated the extension worker in the second village). This, and indeed the findings of the other surveys, if interpreted in the way we suggest, is generally compatible with the conclusions we draw from the group discussions in our own survey. This is that a clear preference was expressed for information which had the endorsement of both the informal communication system and the formal channels. The groups we listened to definitely supported the principle of receiving information via extension services, but they clearly also shared many of the anxieties which the extension agents themselves had about the current functioning of this, and therefore still relied to a considerable extent on traditional sources.

This is further illustrated by responses concerned with the usefulness of radio messages. Radio is a popular and more or less ubiquitous medium in Africa. Various studies also suggest that it is a very significant medium in the transmission of development related information. For example, the MARE Project found that $95.3 \%$ of farmers claimed to listen to agricultural radio programmes (though it did also find that few of them could recall the names of the programmes). ${ }^{36}$ Likewise in one of Mchombu's Malawian villages $35 \%$ of respondents said they were interested in agricultural advisory broadcasts, but only $12 \%$ preferred music and entertainment programmes. ${ }^{37}$ True, there was a majority for music and entertainment in his other village, but the tendency is still to show that radio is very important for agricultural information purposes. We would contend that such findings are very much a construct of the survey process, and that what villagers really feel is much more qualified. When allowed to put things in their own terms, they told us that radio was, in principle, a source of which they took notice, but that their ability to use it, because of the scarcity of receivers, and the extent to which they would rely on it were both somewhat limited. This, we would argue, is typical of the way in which our research complemented the more formal surveys which have been the usual approach to the subject of rural African information and communication.

\section{CONCLUSIONS}

The information providing agencies which serve rural Malawi are essentially geared up for a one-way, top-down flow of information. Not only does this mean that they have limited capacity to respond to expressed demand for information, but also that their messages lose effect from lack of timeliness, insufficient selectivity and targetting. The extension workers perceive that this hinders their work and would generally wish to participate in more effective dissemination of information from the centre and to have more scope to feed back their understanding of local needs and concerns. Despite the strains, an underlying faith in the essentials of the system of communication represented by Malawi's extension 
services is still intact, both amongst the extension agents and the community. Radio, audio-visual aids and other forms of technology-based communication, whilst offering useful supplementation to face-toface contact, are not yet an answer to these difficulties. Likewise, print media have a well-established supporting role in the communication process, which is capable of enhancement.

From this understanding of the situation, we draw the conclusion that there is a substantial contribution that the Malawi National Library Service can make to the alleviation of the problem of information needs in the rural areas. It already has its programme for Rural Community Information Centres, which bring information in print form closer to the villagers themselves, but we believe it can also serve those villagers who cannot read, or who want information mediated by a trusted, locally-based adviser for oral delivery. What this suggests is a need for new programmes, as a complement to existing services, to assist the extension workers become more effective as disseminators of information. The desire for information materials which they could consult to expand, supplement and update their knowledge was one expressed in a number of our interviews with extension workers. It could also be argued that it was implicit in the concerns of many of the others.

Previous writers have tended to suggest that libraries should serve the farmers information needs direct. Gundu Shibanda in writing of agricultural information services in Kenya, for instance, suggested that "Farmers need to have access to adequate information to enable them to understand and assess their own problems. The agricultural library service should collect and provide, through its service points at all levels, various forms of information, including leaflets, books, farm visit notifications, slides, printed [texts of] radio programmes and field notifications." ${ }^{38}$ Kaniki also concluded that libraries "must provide services and information needed and usable by farmers." ${ }^{139}$ We find no indication from our research to lead us to believe that farmers could, or would, use such services in worthwhile numbers.

We do conclude that the enhanced quality of information that could be provided by better informed extension workers would be valued by the rural community. CAB International's appraisal of Malawi's agricultural information needs also provides support for the idea of informing the rural community through better-informed extension workers, although the relevant passage is obscurely phrased. ${ }^{40}$ We believe that a need for appropriate library service to the Extension Planning Area office from which the work of the extension agents is directed, and where they receive their fortnightly training sessions, is manifest. What precise form this might take, in terms of collections or systems of response, would need to be investigated, but almost any service directed in this way, however humble, would show considerable dividends in proportion to the expenditure devoted to it.

\section{NOTES}

1.. The project was a cooperative exercise in July and August 1994 between Malawi National Library Service and the Department of Information Studies at Loughborough University, with financial assistance from the British Council in Lilongwe, Malawi. The authors gratefully acknowledge the assistance of Carolyn Pritchett of Loughborough University in the preparation of this paper, and thank Evelyn Kerslake, also of Loughborough University, for very helpful comments on a draft version.

2...Doob, L.W. Communication in Africa. New Haven, Yale University Press, 1961.

3. Scribner, S. and Cole, M. The psychology of literacy. Cambridge, Mass., Harvaro University Press, 1981.

4.. A study with rich implications for information research, but little cited in the LIS literature, could be mentioned as an instance of this: Amaratunga, $C$. and Shute, J. Extension and adult learning in a Ghanaian community. Canadian Journal of African 
Studies, 16 (1982) 549-566.

5..Adimorah, E.N.0. An analysis of progress made by public libraries as social institutions in Nigeria. UNESCO Journal of Information Science Librarianship and Archives Administration. 5, (1983). p.162.

6..Aboyade, B.0. Communication potentials of the library for non-literates: an experiment in providing information services in a rural setting. Libri. 34, (1984). $243-262$.

7.. Oladele, B.A. Toward an integrated agricultural information consolidation scheme for farmers in the Nigerian rural areas. Quarterly Bulletin of the International Association of Agricultural Librarians and Documentalists. 32, (1987). 98-101.

8...Adimorah, E.N.0. Users and their information needs in Nigeria. Nigerian Library and Information Science Review. 1, (1983). 137-148.

9..Aina, L.0. Information needs and information-seeking involvement of farmers in six rural communities in Nigeria. Quarterly Bulletin of the International Association of Agricultural Librarians and Documentalists. 30, (1985). 35-40.

10..Mchombu, K.J. Information needs and seeking patterns for rural people's development in Africa. Gaborone, Botswana, University of Botswana and IDRC, 1993.

11..Heyd, T. Indigenous knowledge, emancipation and alienation. Knowledge and Policy, 8, (1995). 63-73.

12..37\% of respondents in a survey in Botswana. Mutanyatta, J.N.S. and Mchombu, K.J. The Village Reading Room Services in Botswana: final report of an evaluative study. Gaborone, Botswana National Library Service, 1995.

13. For instance the data on information needs collected in the evaluation of the Ethiopian literacy campaigns. Sjostrom, M. and Sjostrom, R. How do you spell development?: a study of a literacy campaign in Ethiopia. Uppsala, Scandinavian Institute of African Studies, 1983. p151.

14.. Mabomba, R. Developing library and information services to rural communities in Malawi. Masters Dissertation, University of Wales, 1985.

15.. A research programme beginning in 1995, under the direction of George Chimseu, is now evaluating the successes and failures of the Rural Community Information Centres. The programme was awarded the Ulverscroft Munford Research Award, against considerable international competition.

16. . Mchombu, K. Information needs for rural development: the case study of Malawi. African Journal of Library, Archives and Information Science 2, (1992). 17-32.

17..Uta, J. Health communication in rural populations in developing countries: with special reference to Malawi. PhD Thesis, Loughborough University, 1993.

18.. Chambers, R. Chapter Three: How outsiders learn. In: Rural development: putting the last first. Harlow, Essex, Longman, 1983. 47-74.

19..Sturges, P. and Chimseu, G. Qualitative research in information studies: a Malawian Study. Education for Information. 14, (1996) forthcoming.

20.. Khon Kaen University. Proceedings of the 1985 International Conference on Rapid Rural Appraisal. Khon Kaen, Thailand, Rural Systems Research and Farming Systems Research Projects, 1987.

21..Chambers, R. and Guijt, I. PRA five years later: where are we now? Forest, Trees and People Newsletter, 26/27 (1995). 4-14.

22.. Webb, B. My apprenticeship. London, Longman, 1926. Appendix B, The method of interviewing. 361-3.

23. Invaluable assistance with the group interviewing in this area was provided by the very resourceful Kelly Mhone of the local Community Development office.

24. A fuller account of this phase of the project is presented in: Sturges, $P$. and Chimseu, G. Information repackaging in Malawi. African Journal of Library Archives and Information Science, 6 (1996) forthcoming.

25..Mhone, G.C.Z. Malawi at the crossroads: the post-colonial political economy. 
Harare, Sapes Books, 1992. p.19

26. . Malawi Ministry of Agriculture, Evaluation and Action Research Unit. Blantyre ADD Communication Project: Baseline Survey. Lilongwe, Ministry of Agriculture, 1992. p.1.

27..Mpachika, E.D. et al. Contact farmers voice opinions: T. and V. system of extension in Malawi. Journal of Extension Systems. 6 (1990). 67-73.

28..Pelletier, D.L. and Msukwa, L.A.H. Role of information systems in decisionmaking following disasters. Human Organization 49 (1990). 245-254.

29. . Namponya, C.R. Agricultural development and library services. International Library Review. 18 (1986). 267-274.

30. . Malawi Ministry of Agriculture, Evaluation and Action Research Unit. Blantyre ADD Communication Project: Baseline Survey. Lilongwe, Ministry of Agriculture, 1992. p.19.

31..Francis, P. and Rawlins-Branan, M.J. The extension system and small-scale farmers: a case study from Northern Zambia. Agricultural Administration and Extension. 26 (1987). 185-196.

32..Kaniki, A.M. Information seeking and information providers among Zambian farmers. Libri 41 (1991). 147-164.

33.. Mungunda, $S$. and Mumbuna, M.M. Livestock knowledge in Western Province: Part 2, Local knowledge of cattle keepers. Mongu, Zambia, Dept. of Veterinary and Tsetse Control Services, 1992 .

34.. McClymont, D.S. An investigation into the communication of innovation among commercial farmers in Zimbabwe. Unpublished report, no bibliographic details, 1982. Copy in library of Overseas Development Institute, Regent's College, London.

35. Mchombu, K.J. Information needs for rural development: the case study of Malawi. African Journal of Library Archives and Information Science 2 (1992). 17-32.

36. . Malawi Ministry of Agriculture, Evaluation and Action Research Unit. Blantyre ADD Communication Project: Baseline Survey. Lilongwe, Ministry of Agriculture, 1992. p. 20 .

37. . Mchombu, K.J. Information needs for rural development: the case study of Malawi. African Journal of Library Archives and Information Science 2 (1992). p.30.

38. .Shibanda, G. Information for agriculture in Kenya. Information Development (1991). 141-146. p145.

39..Kaniki, A.M. Information seeking and information providers among Zambian farmers. Libri 41 (1991). p161.
40. "If CABI is to be seen as providing services relevant to the needs of its member countries it will be important to provide assistance for information dissemination through the development of a training package aimed at assisting adaptive research and extension workers to identify the issues which currently constrain effective dissemination. Such assistance will strengthen the demands placed on fundamental research to produce results more closely geared to the needs of smallholders and the country's development priorities."

$C A B$ International. Appraisal of country needs for CABI services: Republic of Malawi. Wallingford, Oxfordshire, CAB International, 1992. pp.26-7. 